\title{
TRADISI DUTU PADA PERKAWINAN ADAT SUKU HULONDHALO DI KOTA GORONTALO PERSPEKTIF MAQÂSID AL-SYARÎ'AH
}

\author{
Nurul Mahmudah \\ Fakultas Syariah IAIN Metro Lampung \\ Jl. Ki Hajar Dewantara 15A, Metro Timur \\ Email: mafazasyafira@gmail.com \\ Supiah \\ Fakultas Tarbiyah IAIN Sultan Amai Gorontalo \\ Jl. Jalan Gelatik no. 1, Gorontalo 96112 \\ Email: supiahbd@gmail.com
}

\begin{abstract}
In Gorontalo city there is a tradition of dutu in his traditional marriage. This tradition certainly has philosophical reasons behind it, and one method of knowing the philosophy behind a rule is to use maqaid al-shariah al-Syathibi. The focus of this research is (1) How is the implementation of figh principles in the Hulondhalo tribe in the implementation of the tradition of dutu in customary marriage in the city of Gorontalo (2) How is the review of maqashid al-shariah on the tradition of traditional marriage dutu in the Hulondalo tribe in Gorontalo at a very expensive cost. This type of research is qualitative research, and the form of field research. The results of this study concluded that: (1) the implementation of the fiqh method was evidenced by the implementation of the tradition of the dutu whose procedure was to deliver 1 package of dowry and custom attributes delivered to the bride's house. For the tradition of dutu in the context of modernity, family position is a measure of the value of dowry for the bride and the social achievement of the woman. The higher the social value, the higher the value of the dowry. This is in accordance with the arguments of the hadith of the Prophet. (2) The review of maqashid alshari'ah in this tradition includes the category of maqashid hajiyyat which safeguards maqashid dharuriyyatnya. Marriage as a form of hifz al-nasl which is commanded by Allah. The price of the dowry is in the position of ma'aid tahsîniyyat to glorify a woman as a manifestation of maintaining religion, soul, mind, lineage, and wealth.
\end{abstract}

Keywords: Tradition of dutu, customary marriage, hulondhalo, maqasid al-syari ah

Abstrak: Di kota Gorontalo terdapat tradisi dutu pada perkawinan adatnya. Tradisi ini tentu mempunyai alasan filosofis di baliknya, dan salah satu metode mengetahui filosofis di balik suatu aturan adalah menggunakan maqashid al-syari' ah al-Syathibi. Fokus dalam penelitian ini (1) Bagaimana implementasi kaedah fiqh dalam masyarakat suku Hulondhalo pada pelaksanaan tradisi dutu dalam perkawinan adat di kota Gorontalo (2) Bagaimana tinjauan maqashid al-syari ah terhadap tradisi dutu perkawinan adat pada suku Hulondalo di kota Gorontalo yang masih menerapkan dengan biaya yang sangat mahal. Jenis penelitian ini adalah penelitian kualitatif, dan bentuknya field research. Hasil penelitian ini menyimpulkan bahwa: (1) implementasi kaedah fikih dibuktikan dengan adanya pelaksanaan tradisi dutu yang tata caranya yaitu mengantarkan 1 paket mahar dan atribut adat yang diantarkan ke rumah pengantin wanita. Untuk tradisi dutu dalam konteks modernitas, jabatan keluarga menjadi tolok ukur nilai mahar untuk calon pengantin wanita, dan pencapaian sosial dari wanita tersebut. Semakin tinggi harkat sosialnya, maka semakin tinggi pula nilai maharnya. Hal ini sesuai dengan dalil hadis Rasulullah saw. (2) Tinjauan maqashid al-syari ah pada tradisi ini termasuk kategori maqashid hajiyyat yang menjaga maqashid dharuriyyatnya. Perkawinan sebagai wujud hifz alnasl yang diperintahkan Allah. Besarnya harga mahar berada di posisi maqashid tahsinniyyat untuk memuliakan seorang wanita sebagai wujud dari memelihara agama, jiwa, akal, keturunan, dan harta.

Kata kunci: Tradisi dutu, perkawinan adat, hulondhalo, maqashid al-syari’ah

\section{Pendahuluan}

Dalam sebuah perkawinan terdapat pemberian mahar dengan beberapa proses pra per- kawinan, yang pertama adalah lamaran. Pada hakikatnya terdapat kesamaan pemberian mahar, namun perbedaan-perbedaannya ter- 
dapat pada alat atau sarana pendukung dari proses itu. ${ }^{1}$ Bila peminangan atau lamaran telah diterima dengan baik oleh pihak yang dilamar, maka mungkin tidak sekaligus mengakibatkan perkawinan, akan tetapi mungkin dilakukan pertunangan terlebih dahulu.

Menurut hukum adat, suatu perjanjian dapat terjadi antara pihak yang saling berjanji atau karena sifatnya dianggap ada perjanjian. Dalam perkawinan di daerah Gorontalo, khususnya suku Hulondhalo, sebelum melakukan perkawinan, implementasi kaedah fiqh العادة حكمة terdapat pada prosesi pra nikah yang mewajibkan setiap calon pengantin pria untuk datang ke rumah calon pengantin wanita. Adat istiadat suku Hulondhalo sangat dipengaruhi ajaran Islam. Karenanya masyarakat Gorontalo memegang teguh semboyan adat yaitu Adati hula hula Sareati - Sareati hula bula to Kitabullahs yang artinya "Adat Bersendikan Syara', Syara' Bersendikan Kitabullah".

Dalam Inpres No 1/1991 tentang Kompilasi Hukum Islam tercantum pembahasan tentang mahar yang menjelaskan bahwa pemberian mahar ini hukumnya wajib yang jumlah, jenis, dan bentuknya disepakati oleh kedua belah pihak. Adapun penentuan mahar, wajib didasarkan pada asas kesederhanaan dan kemudahan yang diajurkan dalam ajaran Islam. ${ }^{2}$ Maqâshid alsyarîah al-Syathibi ${ }^{3}$ memaparkan bahwa pada hakikatnya misi kerasulan Muhammad saw ke dunia adalah untuk meraih kebaikan (maslahah) dan menghindari keburukan (mafsadah) pada segala tindak tanduk umat manusia.

Jenis penelitian yang digunakan dalam penelitian ini adalah jenis penelitian hukum empiris, kemudian metodenya menggunakan penelitian field research (penelitian lapangan). Penelitian dilakukan di Provinsi Gorontalo,

${ }^{1}$ Soerjono Soekanto, Hukum Adat, (Jakarta: Raja Grafindo persada, 2012), Cet.ke-12, h. 223.

${ }^{2}$ Point d Pasal 1 Bab I Buku I Dan Pasal 30 Dan 31 Bab V, Abdurrahman, Kompilasi Hukum Islam (Jakarta: Akademika Pressindo, 2000).

3 Saputra, Adang, Hermeneutika Maqâshid Imam alShâthibî, Wawasan: Jurnal Ilmiah Agama dan Sosial Budaya, Vol 2, No 1 (2017), Fakultas Ushuluddin UIN Sunan Gunung Djati Bandung. khususnya di kota Gorontalo. Penelitian ini terfokus pada perilaku masyarakat suku Hulondhalo pada adat suku Hulondhalo tentang proses peminangan. Sumber data adalah subjek darimana data tersebut diperoleh ${ }^{4}$ Sumber data primer $^{5}$ yaitu berupa hasil wawancara dengan orang-orang yang berhubungan dengan penelitian ini, yaitu pelaku pelaksanaan tradisi dutu, para tokoh adat suku Hulondhalo, dan pakar hukum Islam kota Gorontalo. Data sekunder yaitu Alquran, hadis, Kompilasi Hukum Islam tentang mahar, kitab al-Muwafaqat karya alSyathibi, dan UU No. 1 Tahun 1974 yang terkait tentang mahar.

Adapun untuk pengumpulan data dalam penelitian ini, peneliti menggunakan beberapa teknik seperti wawancara ${ }^{6}$ dan dokumentasi. ${ }^{7}$ Dalam menganalisis hasil data yang didapatkan, peneliti menggunakan tahapan-tahapan analisis data yaitu pengeditan, klasifikasi, verifikasi, analisis ${ }^{8}$ dengan model analisis data Miles dan Huberman, yaitu pertama. mereduksi data yang telah didapatkan; kedua, melakukan penyajian data agar data tidak berantakan. ${ }^{?}$

Dalam pengecekan keabsahan data, Lexy J. Moleong memberikan beberapa opsi/cara untuk mengkaji keabsahan data menggunakan triangulasi yaitu pengecekan atau pemeriksaan keabsahan data yang memanfaatkan sesuatu yang lain, seperti sumber, metode, penyidik dan teori. ${ }^{10}$ Kemudian membandingkan apa yang dikatakan dengan apa yang dipraktikkan, membandingkan dan mengecek suatu informasi yang diperoleh dari informan yang satu ke informan lainnya, dan membandingkan hasil wawancara dengan data sekunder yang telah didapat.

4 Lexy. J. Moleong, Metodologi Penelitian Kualitatif, (Bandung: PT Rosda Karya, 2006), h.129

${ }^{5}$ Lexy. J. Moleong, Metodologi Penelitian..., h. 112.

6 Abu Achmadi, Cholid Narkubo, Metode Penelitian, (Jakarta: PT. Bumi Aksara, 2005), h. 83.

${ }^{7}$ M. Nazir, Metode Penelitian, (Jakarta: Ghalia Indonesia, 2003), h. 194.

8 Masri Singaribun, Sofyan, Metode Penelitian Survey, (Jakarta: LP3ES, 1987), h. 263.

${ }^{9}$ Cik Hasan Bisri, Penuntutan Penyusunan Rencana Penelitian, (Jakarta: PT Raja Grafindo Persada, 2003), h. 66.

${ }^{10}$ Lexy J. Moleong, Metodologi Penelitian..., h. 330-331 


\section{Tradisi Dutu (Mahar) Pada Perkawinan Adat Suku Hulondalo}

Depito dutu ini suatu prosesi adat perkawinan suku Gorontalo, di mana keluarga calon pengantin pria mengantar mahar perkawinan kepada calon pengantin wanita. Prosesi tradisi dutu ini akan dilaksanakan setelah ada prosesi negosiasi antara dua belah pihak pengantin tentang biaya mahar untuk calon pengantin wanita dalam acara Tolobalango.

Semua mahar ini dipersiapkan dengan menggunakan atribut adat sebagai berikut ${ }^{11}$ : Kola-Kola, Tonggu, Tonelo, Tutu Lo Polidulu, Bunggato, Luwalo, Buwalo lo Umonu, Heyi Lo HuheputoLo O'Ato, Dudelo, Tilolom, Wulo lo O'Ato, Wu'Adu Ta'Ato. Setelah prosesi ini dilakukan, maka prosesi Tradisi Dutu telah sempurna untuk dapat dilanjutkan pada tahap adat perkawinan adat suku Hulondhalo selanjutnya yaitu Bate. Deka Usman menjelaskan kepada penulis bahwa nominal besaran mahar diukur dari tingkat sosial menurut penjelasan ${ }^{12}$ yaitu Sejak dahulu hingga saat ini masyarakat suku Hulondhalo mengenal 4 golongan penduduk yaitu pertama, golongan para Raja dan keluarganya, yang disebut dengan Olongiya; kedua, golongan para bangsawan dari keluarganya yang disebut Wali-Wali; ketiga, golongan rakyat biasa dan keluarganya; keempat, golongan budak yang disebut Wao. Dalam konteks modernitas, pemaknaan golongan ini mengalami perubahan berdasarkan demografi. Untuk golongan pertama saat ini, Raja dikiaskan dengan Pejabat Negara/Daerah seperti Presiden, Gubernur dan Menteri. Untuk golongan kedua dikiaskan dengan pengusaha besar dan tokoh agama terkemuka. Untuk golongan ketiga dikiaskan dengan pegawai negeri sipil biasa ataupun wiraswasta. Dan terakhir untuk golongan kedua tetap pada rakyat biasa.

${ }^{11}$ Wawancara dengan Bate Deka Usman, Tokoh Adat Kota Gorontalo, tanggal 10 Desember 2016 diperkuat dengan buku karya Medi Botituhe, Tata Upacara Adat Gorontalo, (Gorontalo; Generasi Penerus, 2003), h.157-159.

${ }_{12}$ Wawancara dengan Bate Deka Usman, Tokoh Adat Kota Gorontalo, tanggal 10 Desember 2016.
Sedangkan perubahan selanjutnya untuk konteks modernitas, tidak hanya jabatan keluarga yang menjadi tolok ukur nilai mahar yang akan didapatkan calon pengantin wanita. Penulis mendapatkan beberapa informasi dari informan selaku pelaku perkawinan yang menggunakan tradisi dutu dalam perkawinan adat suku Hulondhalo dalam prosesinya. Tentang perbedaan antara pelaksanaan tradisi dutu konteks tradisional dengan pelaksanaan tradisi dutu pada konteks modernitas pada perkawinan adat suku Hulondhalo di kota Gorontalo ini:

a. Dalam segi tata cara pelaksanaan tidak ada perubahan yang spesifik.

b. Dalam segi kebendaan, ada perubahan yaitu bergantinya kebendaan dari paket mahar beserta buah-buah, diganti menjadi uang dengan nominal yang lebih besar.

c. Dalam segi kesepakatan, ada perubahan yang spesifik yaitu tentang nilai besarnya mahar yang diberikan pada konteks tradisional hanya dilihat dari status jabatan orang tua, namun untuk konteks modernitas, tidak hanya dilihat dari status jabatan orang tua, melainkan dari status keberhasilan akademik maupun sosial dari seorang calon pengantin wanita. Semakin tinggi pencapaiannya, maka semakin tinggi pula harga maharnya.

Adapun alasan filosofis yang melatarbelakangi prosesi tradisi dutu (mahar) pada perkawinan adat suku Hulondalo dengan biaya yang sangat mahal dilihat dari tiga sisi. Pertama, menurut Bate Deka Usman, alasan filosofis dari sisi nilai terlihat dari dasar hukum yang digunakan suku Hulondhalo pada tradisi ini adalah Alquran. Berdasarkan pemaparan dari Bate Deka Usman ${ }^{13}$ dasarnya surat al-Nisa ayat 4 yang maknanya berilah perempuan yang akan kamu kawini itu suatu pemberian. Allah berfirman:

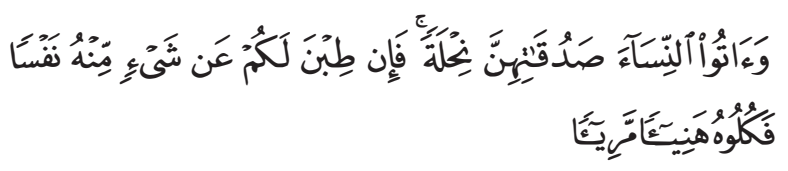

13 Wawancara dengan Bate Deka Usman, tokoh adat kota Gorontalo, tanggal 10 Desember 2016 
"Berikanlah maskawin (mahar) kepada wanita (yang kamu nikahi) sebagai pemberian dengan penuh kerelaan. Kemudian jika mereka menyerahkan kepada kamu sebagian dari maskawin itu dengan senang hati, maka makanlah (ambillah) pemberian itu (sebagai makanan) yang sedap lagi baik akibatnya".

Hadis selanjutnya dipaparkan oleh Bate Deka Usman tentang apa yang dikatakan Aisyah perihal mahar Nabi Muhammad saw: "Aisyah berkata, "Mahar Rasulullah kepada para isteri beliau adalah 12 Uqiyah dan satu nasy". Aisyah berkata, "Tahukah engkau apakah nasy itu?". Abdur Rahman berkata,"Tidak". Aisyah berkata, "Setengah Unqiyah". Jadi semuanya 500 dirham. Inilah mahar Rasulullah saw kepada para isteri beliau." Selanjutnya alasan filosofis kedua dari sisi mitologi terlihat dari kewajiban pelaksanaan tradisi dutu ini memiliki nilai tersendiri bagi suku bulondhalo. Perkawinan yang dilaksanakan sesuai adat adalah perkawinan tanpa cacat dan tanpa sanksi, dalam artian menurut peneliti jika tidak sesuai dengan adat, maka adanya kecacatan dan sanksi berlaku pada pengantin. Adapun sumpah adat yang menyertai pengesahan adat itu sendiri menurut Bate Deka Usman yaitu sebagai berikut :

"Adati ma Dili-Dilito, Bolo Mopo'ayito

Adati ma Hunti-Huntingo, Bolo Mopodembingo

Didu ma Boli-Boliya, Teto teya, Paku-paku lo

Tadiya

Wonu Boloboliolo, mo'otinu tutumulo

Mo'opate pilimulu"

Sebaliknya, perkawinan yang tidak dilakukan secara adat di kawasan suku Hulondhalo, maka terdapat sanksi lahir maupun batin, bahwa perkawinan tersebut dapat terjadi kesulitan atau masalah yang tidak kunjung habis. Kemudian alasan filosofis ketiga dari sisi tradisi terlihat dari kebiasaan yang digunakan suku Hulondhalo pada tradisi ini. Seperti paparan dari Bate Deka Usman tentang alasan filosofisnya ini ${ }^{14}$. Faktor tambahan di antaranya pada masyarakat ekonomi asean (MEA) ini,

${ }^{14}$ Wawancara dengan Bate Deka Usman, tokoh adat kota Gorontalo, tanggal 12 Desember 2016. suku Hulondhalo di kota Gorontalo merupakan suku yang mayoritasnya berpendidikan tinggi. Masyarakat yang berpendidikan lebih tinggi memiliki standar khusus dalam setiap pribadi masing-masing. Di samping itu, tingkat ekonomi mereka berkembang pesat, inflasi di Gorontalo dengan kebutuhan yang banyak mengakibatkan perlunya memberikan mahar yang tinggi, karena semakin besar acara yang dilakukan, maka terlihat semakin sejahtera keluarga tersebut. Dalam hal kesetaraan gender, perempuan diberikan perhatian khusus sehingga mendapatkan posisinya yang tidak dipandang sebelah mata oleh laki-laki. Sehingga perempuan tidak sembarangan untuk dinikahi”

\section{Tradisi Dutu Perspektif Maqâshid al-Syarîah}

Hukum Islam merupakan hukum yang dibuat untuk kemaslahatan hidup manusia. Bagi kehidupan manusia, apapun yang diperbuat dan dipermasalahkan maupun aturan yang dibuat untuk menata kehidupan manusia, hukum Islam mampu memberikan jalan keluar dan petunjuk termasuk menyikapi perkembangan dan perubahan yang terjadi di masyarakat. $\mathrm{Hal}$ inilah yang menyebabkan pentingnya mempertimbangkan modernitas dalam hukum Islam. Terbentuknya hukum Islam yang mengatur segala tindak tanduk perilaku hidup manusia karena adanya perubahan masyarakat yang selalu terjadi, baik secara tatanan sosial, budaya, sosial ekonomi dan lainnya. Hal ini dijeaskan pada kaidah fikih yang berbunyi:

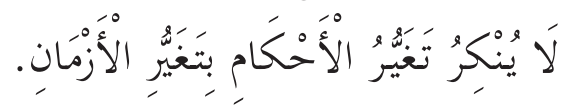

"Tidak dapat diingkari adanya perubahan hukum akibat berubahnya masa."

Tradisi dutu pada perkawinan adat suku Hulondhalo menggunakan prosesi pemberian mahar sebelum melakukan akad nikah atau dukhul, merupakan jenis Mahar Mu'ajjal yang merupakan mahar yang dibayar secara kontan semuanya sebelum suami isteri itu melakukan hubungan badan (dukhul). Maqashidal-syari ah secara istilah adalah tujuan-tujuan syariat Islam 
yang terkandung dalam setiap aturannya. AlSyathîbî mengungkapkan tentang syari`ah dan fungsinya bagi manusia seperti ungkapannya dalam kitab al-Muwafaqat:

$$
\begin{aligned}
& \text { هذه الشريعة .... وضعت لتحقيق مقاصد الشارع في } \\
& \text { قيام مصالحهم في الدين والدنيا معا }
\end{aligned}
$$

"Sesungguhnya syariat itu ditetapkan bertujuan untuk tegaknya (mewujudkan) kemashlahatan manusia di dunia dan akhirat".

Pendekatan maqâshid al-syarîah terhadap tradisi dutu pada perkawinan adat suku Hulondhalo dilakukan agar hukum Islam mampu mewujudkan kemaslahatan dalam setiap aspek kehidupan manusia di segala tempat dan waktu. Dalam penjelasan kaidah usul fikih bahwa kebiasaan dalam masyarakat yang timbul sebagai akibat adanya modernitas dapat dijadikan sebagai hukum baru selama kebiasaan tersebut sejalan dengan prinsip-prinsip ajaran Islam. Seperti kaidah usul fikih:

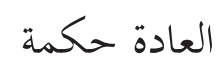

\section{"Adat yang (dapat) menjadi sumber hukum"}

Al-Syathîbî meletakkan posisi maslahat sebagai illat hukum atau alasan pensyariatan hukum Islam. Sesuai prinsip maqâshid al-Syarîah al-Syathîbî yaitu mengutamakan kemaslahatan umum, dapat dipahami bahwa segala modernisasi yang terjadi pada segala bentuk pola hidup masyarakat, khususnya perubahan pelaksanaan tradisi dutu pada perkawinan adat suku Hulondhalo. dari konteks tradisional menuju pada konteks modernitas tidak dilarang oleh syariat Islam. Sebab tradisi ini tidak bertentangan dengan tujuan maqâshid al-Syarîah dan malah memberikan kemaslahatan bagi pelakunya, ini sebagaimana hasil wawancara dan paparan data penulis dari informan.

Selanjutnya sebelum menganalisa menggunakan maqâshid al-Syarîah al-Syathîbî tentang posisi tradisi $d u t u$, perlunya penulis menganalisa tafsiran ayat Alquran dan hadis yang dimaksud informan menjadi alasan filosofis dari mengapa tradisi $d u t u$ pada perkawinan adat suku Hulondhalo ini masih dilakukan dalam konteks modernitas.

Adapun salah satu landasan dasar dari kewajiban memberikan mahar kepada wanita dengan ketentuan yang berlaku, dari sini peneliti mencoba untuk menafsirkan makna dari ayat di bawah ini:

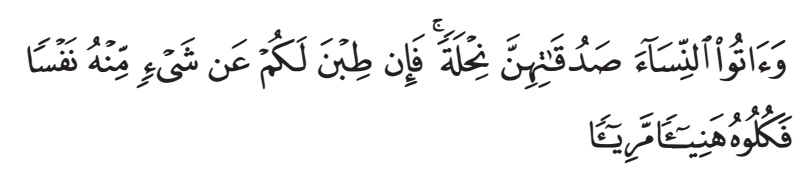

"Berikanlah mas kawin (mahar) kepada wanita (yang kamu nikahi) sebagai pemberian dengan penuh kerelaan. Kemudian jika mereka menyerahkan kepada kamu sebagian dari mas kawin itu dengan senang hati, maka makanlah (ambillah) pemberian itu (sebagai makanan) dengan penuh kelahapan lagi baik akibatnya."

Perintah memberikan mahar tidak hanya tertuju bagi suami yang mengawini perempuan, tetapi juga untuk orang tua. Hal ini karena dalam tradisi Arab jahiliah, anak perempuan itu seperti diperdagangkan. Kalau mau menikahkan, orang tua minta mahar yang mahal agar bisa menguasai harta tersebut. Bahkan tradisi buruk semacam itu masih berlangsung sampai sekarang di beberapa kalangan masyarakat. Dari sini Islam dengan tegas menghapus tradisi itu, dan mahar dijadikan hak mutlak wanita (istri). ${ }^{15}$

Selanjutnya tentang kewajiban pembayaran jumlah mahar pada masyarakat suku Hulondhalo, dapat disimpulkan bahwa suku Hulondhalo pada konteks modernitas ini memahami tentang besarnya mahar yang ideal dan wajib diberikan melalui hadis tersebut, sebesar mahar yang diberikan Rasulullah kepada istri-istrinya ketika hendak mengawininya. Karena Rasulullah merupakan nabi yang didaulat otomatis sebagai suri teladan terbaik, dengan maksud mencontoh beliau, ini yang membuat suku Hulondhalo mengartikan wajibnya memberikan harga diri tinggi terhadap wanita di Gorontalo, khususnya kota Gorontalo.

15 Muhammad Nasib al-Rifa'i.Tafsir al-Aliyy al-Qadir li ikhtishari Tafsir Ibn Katsir. Terj. Drs. Syihabuddin, (Jakarta: Gema Insani, 2007), h. 656. 
Bagi yg mampu atau kaya tidak akan mendapatkan kesulitan dengan niai mahar tersebut. Menurut hadits yang diriwayatkan oleh Imam Muslim diceritakan bahwa mahar yang diberikan Nabi Muhammad saw adalah berupa uang sebanyak 500 dirham. ${ }^{16}$

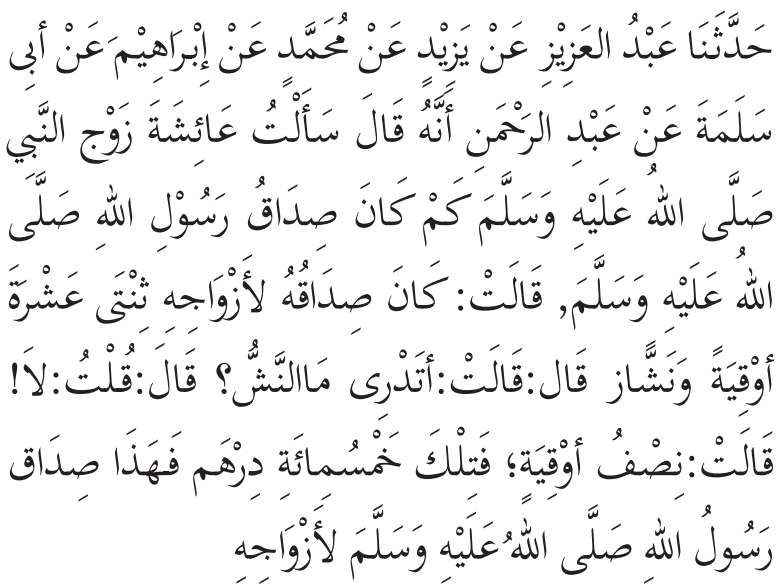

"Telah menceritakan pada kami Abdul Aziz dari Yazid dari Muhammad dari Ibrahim dari Abi Salamah dari Abdur Rahman bahwa sesungguhnya dia berkata: saya telah bertanya kepada Aisyah isteri Rasulullah saw., berapa jumlah mas kawin Rasulullah saw.? Aisyah berkata: mas kawin Rasulullah saw kepada para isteri beliau adalah 12 auqiyah dan satu nasy. Aisyah berkata: Tahukah engkau apakah nash itu? Abdur Rahman berkata: Aku berkata: Tidak! Aisyah berkata: Setengah auqiyah. Jadi semuanya 500 dirham. Inilah mas kawin Rasulullah saw kepada para isteri beliau.

Adapun bagi yang kurang mampu, maka terdapat hadits-hadis yg menunjukkan nilai mahar yang lebih rendah dari nilai mahar sesuai strata wanita dengan ukuran sebanding tingkat kekayaan/penghasilan pria tersebut. Dalam beberapa hadis disebutkan, ada kaum muslimin yang maharnya adalah sepasang sandal karenajika memang saat itu hanya itulah kemampuannya. Sedangkan mahar Fatimah puteri Rasulullah berupa sebuah baju besi, karena hanya itu harta berharga yang dimiliki oleh Ali bin Abi Thalib ra. pada saat menikah. Sebab pada saat itu Ali bin Abu Thalib masih dalam kondisi ekonomi yang sangat kurang.

\footnotetext{
${ }^{16}$ Sahih Muslim Juz 1, h. 597
}

Menurut teori Al-Syatibi, tradisi dutu yang ditetapkan dalam perkawinan adat suku Hulondhalo mengenai mahar, harus dapat mewujudkan kemaslahatan hamba (mashalih al-ibad), baik di dunia maupun di akhirat. Kemaslahatan inilah, dalam pandangan alSyatibi, menjadi maqashid al-syariah. Dengan kata lain, penetapan aturan hukum, baik secara keseluruhan maupun secara rinci, didasarkan pada suatu motif penetapan hukum, yaitu mewujudkan kemaslahatan hamba. ${ }^{17}$ Maqâshid alSyarîah sendiri yang menjadi tujuan disyariatkannya hukum Islam, mempunyai lima tujuan pokok (menjaga agama, jiwa, keturunan, harta, dan akal.). Segala sesuatu yang mendukung tercapainya kelima tujuan pokok tersebut, harus didukung. Dan segala sesuatu yang bertentangan dengan salah satu dari kelima tujuan itu, harus dicegah.

Dalam perkawinan, perlindungan terhadap agama (حفظ الدين) adalah merupakan salah satu unsur yang dipelihara oleh syariat. Demi memelihara dan menjaga agama seorang hamba Tuhan di dunia, dalam mahar yang ditentukan dalam tradisi dutu ini perlu dikaji kembali kemaslahatannya. Perlindungan terhadap kepribadian diri yang menjadi syarat tersebut, jika dikaitkan dengan maqâshid al-syarîah maka termasuk dalam kategori pemeliharaan jiwa (حفظ النفس). Dalam tradisi dutu ini, tujuannya memelihara jiwa ialah memelihara hak calon pengantin wanita untuk hidup secara terhormat dan memelihara jiwa agar terhindar dari tindakan penganiayaan, termasuk dalam menghadapi berbagai permasalahan yang akan muncul dalam rumah tangga. Dalam hubungan suami-istri termasuk menjaga dan memelihara keseimbangan hak dan kewajiban, selalu memperhatikan kesetaraan dan keadilan gender di antara keduanya, saling membantu dan bekerjasama dalam mengatasi berbagai urusan dalam rumah tangga. ${ }^{18}$

${ }^{17}$ Al- Syatibi, al-Muwa faqat fi Ushul al-Syari' ah, (Kairo: Mustafa Muhammad, t.th.), jilid II, h. 2-3.

${ }^{18}$ Ahmad al-Mursi Husain Jauhar, Maqâshid Syarîah, h. 125 
Selanjutnya dalam tradisi dutu Ini memberikan terjaminnya akal agar mampu berpikir dengan bijaksana dalam mengatasi permasalahan yang terjadi dalam rumah tangganya. Ini juga tergolong perlindungan terhadap akal (فظ العقل). Akal adalah bagian penting dari tujuan syariat yang harus dilindungi dari kerusakannya. Upaya pencegahan yang bersifat preventif yang dilakukan syariat Islam, sesungguhnya ditujukan untuk meningkatkan kemampuan akal pikiran dan menjaganya dari berbagai hal yang membahayakannya, seperti fitnah dari orang yang mengganggap murahnya mahar disebabkan oleh kehamilan atau hal lainnya. ${ }^{19}$

Dalam perkawinan, perlindungan terhadap keturunan (حفظ النسل) adalah merupakan salah satu unsur yang dipelihara oleh syariat demi memelihara dan menjaga keturunan di dunia. Pada mahar yang ditentukan dalam tradisi Dutu ini perlu dikaji kembali kemashlahatannya. ${ }^{20}$ Tujuan maqâshid al-syarîah al-Syathîbî selanjutnya dalam menciptakan kemaslahatan manusia adalah dalam hal memelihara harta (حفظ المال). Manusia termotivasi untuk mencari harta demi menjaga eksistensinya dan demi menambah kenikmatan materi. Dalam hal ini, dapat dicermati bahwa untuk mewujudkan tujuan dari tradisi dutu ini yaitu menghindari dari masalah ekonomi dan untuk membentuk keluarga yang bahagia dan kekal, diperlukan tahap memuliakan wanita dengan mahar. Namun, besar nilainya yang ditentukan oleh keluarga pihak wanita menjadikan nilai kemaslahatannya berkurang, karena di sini peneliti menilai bahwa suku Hulondhalo menjadikan mahar sebagai kunci utama dari kesuksesan sebuah perkawinan.

Seperti ketentuan lain dalam Inpres No 1/1991 tentang Kompilasi Hukum Islam yang mencantumkan pembahasan tentang mahar, penentuan mahar wajib didasarkan pada asas kesederhanaan dan kemudahan yang dianjurkan dalam ajaran Islam. Selanjutnya, analisa penulis tentang posisi tradisi dutu pada hal yang ber-

${ }^{19}$ Ahmad al-Mursi Husain Jauhar, Maqâshid Syar̂̀ ah, h. 91.

${ }^{20}$ Abdul Manan, Aneka Masalah Hukum Perdata Islam di Indonesia, (Jakarta: Kencana, 2014), Cet. IV, h. 11. sifat dharuriyat, hajiyat serta tabsiniyat yang merupakan urutan hirarkis skala prioritas ketika terjadi benturan antara satu maslahah dengan maslahah yang lain. Tentang posisi tradisi dutu sesuai kebutuhan, menurut maqâshid syarîah al-Syathîbî, pemberian mahar kepada wanita adalah kewajiban yang harus dilakukan secara makruf, hal ini dimaksudkan untuk menjaga maqâshid dharûriyat yang ditimbulkan dalam prosesi perkawinan tersebut. Untuk jumlahnya, menurut penulis hanyalah maqâshid tahsiniyat yang tidak perlu diwajibkan membayarnya menurut status strata dan jabatan, sebab telah dijelaskan bahwa Allah memerintahkan kepada mereka untuk memberikan mahar kepada wanita/istri sebagai pemberian suka rela.

\section{Penutup}

Implementasi kaedah fikih العادة حكمة terdapat pada perubahan pelaksanaan tradisi dutu dalam konteks modern, termasuk kategori maqashid hajiyyat yang menjaga maqashid dharuriyyat-nya perkawinan sebagai wujud hifz al-nasl yang diperintahkan Allah. Besarnya harga mahar berada di posisi maqashid tahsiniyyat untuk memuliakan seorang wanita sebagai wujud dari hifz al-din, hifz al-nafs, hifz al-'aql, hifz al-nasl, dan hifz al-mal.

\section{Pustaka Acuan}

Abdurrahman, Kompilasi Hukum Islam, Jakarta: Akademika Pressindo, 2000

Achmadi, Abu Dan Cholid Narkubo, Metode Penelitian, Jakarta: PT. Bumi Aksara,2005.

Barr, Ibnu Abd al- Al-Kafi fi Fighi Abli AlMadinah, jilid 2

Batubara, Sahmin, "Dialektika Hukum Islam Dan Adat Tentang Perkawinan", Jurnal Tajdid, Vol. 13, No. 1 (2015)

Bisri, Cik Hasan. Penuntutan Penyusunan Rencana Penelitian, Jakarta: PT Raja Grafindo Persada, 2003.

Manan, Abdul, Aneka Masalah Hukum Perdata Islam di Indonesia, Jakarta: Kencana, 2014, Cet. IV. 
Mansur, Mansur. 'Urf dan Pembentukan Hukum Islam Menurut Al-Syâtibî, Lisan al-Hal: Jurnal Pengembangan Pemikiran dan Kebudayaan, Vol. 7, No. 2 (2015)

Mas'ud, Muhammad Khalid, Filsafat Hukum Islam dan Perubahan Sosial, terj. Yudian W. Asmin, Surabaya: Al Ikhlas, 1995.

Moleong, Lexy J., Metodologi Penelitian Kualitatif, Bandung: PT Rosda Karya, 2006.

Nazir, M., Metode Penelitian, Jakarta: Ghalia Indonesia, 2003.

Rifa'i, Muhammad Nasib al-. Tafsir al-Aliyyul Qadir li Ikhtishari Tafsir Ibnu Katsir. Terj. Syihabuddin, Jakarta: Gema Insani, 2007.
Saputra, Adang, Hermeneutika Maqâshidî Imam al-Shâthibî, Wawasan: Jurnal Ilmiah Agama dan Sosial Budaya, Vol 2, No. 1 (2017) Fakultas Ushuluddin UIN Sunan Gunung Djati Bandung.

Singarimbun, Masri, Sofyan, Metode Penelitian Survey, Jakarta: LP3ES, 1987.

Soekanto, Soerjono, HukumAdat, Jakarta: Ptraja Grafindopersada, 2012.

Syatibi, Abu Ishaq al- al-Muwa faqat fi Ushhul al-Syariah, Kairo: Mustafa Muhammad, t.th., jilid, II. 